involved. Parents will usually not accept from a neurologist the reality of their own behavior as a factor in the child's disorder. The expertise of a psychologist or psychiatrist is required when parental conflict is suspected.

\title{
MILD HEAD INJURY AND COGNITIVE DEFICIT
}

The effect of mild head injury in 78 preschool children on their cognitive performance, especially reading ability, evaluated one year after injury and at 6.5 years of age was investigated at the Department of Neurosurgery, Auckland Hospital, New Zealand. Compared to a control group with minor injury not involving the head, head injured preschoolers showed impairment of interpretation of visual puzzles, a visual closure test, and increased incidence of reading difficulties at 6 and 12 months after injury and at age 6.5 years. Another head injury occurred within 6 months in $14 \%$ of the head injured group compared to $<1 \%$ of the control group. Reading ability was correlated with the scores on visual closure at one year after injury. (Wrightson P et al. Mild head injury in preschool children: evidence that it can be associated with a persisting cognitive defect. I Neurol Neurosurg Psychiatry October 1995;59:375-380). (Respond: Mr Philip Wrightson, 18 Crocus Place, Remuera, Auckland 1005, New Zealand).

COMMENT. Mild head injury, not sufficient to require admission for observation, may result in cognitive deficits and impairment of reading and school performance. In this study, the development of visual skills necessary for reading appeared to be interrupted by the injury.

In a previous report reviewed in Progress in Pediatric Neurology I, (PNB Publishers, 1991, p408), mild head injury in 114 school aged children did not have an adverse effect on global measures of cognition and achievement at one to five years after injury. Children with head injuries were indistinguishable from uninjured children on all tests except the teachers' report of hyperactivity which was $4 / 10$ of a standard deviation higher. (Bijur PE et al. Pediatrics 1990;86:337). Hyperactivity noted after head injury might be significant and worthy of careful follow-up and management.

\section{BRAIN NEOPLASMS}

\section{MIGRAINE EPISODES FOLLOWING CRANIAL IRRADIATION}

Complicated migraine-like episodes occurring 1.2 to 2.8 years after cranial irradiation and chemotherapy for brain tumor are reported in four children treated at the Children's National Medical Center, Washington, DC. Three had neuroectodermal tumors and one an ependymoma in the posterior fossa. Headaches lasted 2 to 24 hours and were intermittent, unilateral, and associated with nausea, visual loss, hemiparesis, aphasia, or hemisensory loss. MRIs were unchanged, and CSF, EEGs, EKGs, and MR angiograms were normal. Cerebral angiograms in 3 children were normal but caused recurrence of temporary migraine-like episodes complicated by delirium. Response to propranolol and aspirin was good in 1 and partial in 3. (Shuper A, Packer RJ et al. 'Complicated migraine-like episodes' in children following cranial irradiation and chemotherapy. Neurology Oct 1995;45:1837-1840). (Reprints: Dr Roger J Packer, Department of Neurology, Children's National Medical Center, 111 Michigan Ave, NW, Washington, DC 20010). 
COMMENT. Clinical manifestations of cranial irradiation toxicity can occur in three stages: 1) acute increase in intracranial pressure related to brain edema; 2) subacute 'somnolence syndrome' developing after a 1 to 3 month interval and related to demyelination; and 3 ) chronic focal neurologic deficits, seizures, and cognitive, developmental, and endocrine deficiencies, caused by vascular damage and tissue necrosis and appearing months to years after radiation therapy. The delayedonset headaches reported in the above patients were vascular in type but were unassociated with demonstable vascular damage. The authors caution that cerebral angiography may exacerbate the migraine-like episodes.

Stroke as a late sequela of cranial irradiation for childhood brain tumors was reported in 11 children treated at the Southern California School of Medicine, Los Angeles (Mitchell WG et al. 1991). The addition of chemotherapy may potentiate damage to endothelial cells produced by irradiation causing a mineralizing microangiopathy. For a review of adverse effects of cranial irradiation and chemotherapy in the treatment of brain neoplasms, see Progress in Pediatric Neurology II, PNB Publishers, 1994, pp339-344).

\section{BRAINSTEM TUMORS AND NEUROFIBROMATOSIS I}

Seventeen children with neurofibromatosis type 1 (NF1) and MRI evidence of brainstem tumor are reported from the Children's Hospital of Philadelphia, PA. The mean age of diagnosis of NF1 was 55 months, and of brainstem tumor, 101 months. Headache was the most frequent complaint affecting 53\%, motor incoordination (41\%), cranial neuropathies (35\%), dysarthria (29\%), hemiparesis (12\%), papilledema (12\%), ataxia (12\%), head tilt $(12 \%)$, and seizures occurred in $6 \%$. The primary tumor site was in the medulla in $82 \%$, in contrast to the pontine location in non-NF1 patients with brainstem tumor. Shunt placement for hydrocephalus was required in $41 \%$, more frequent than in non-NF1 patients. Only $18 \%$ had clinical signs of progression. At a median follow-up of 52 months, 15 of 17 were alive. (Molloy PT et al. Brainstem tumors in patients with neurofibromatosis type 1: a distinct clinical entity. Neurology October 1995;45:1897-1902). (Reprints: Dr Patricia T Molloy, Division of Neurology, Children's Hospital of Philadelphia, 324 South 34th Street, Philadelphia, PA 19104).

COMMENT. Brainstem tumors in children with NF1 present with headache and cranial nerve palsies, they are often complicated by symptomatic hydrocephalus, are usually located in the medulla, and pathologically are benign or malignant astrocytomas, with variable outcome but usually prolonged survival. They can be distinguished from the typical NF-1 high-intensity foci on T2-weighted MRI (UBOs) by their mass effect and enhancement with gadolinium. Therapeutic intervention should be withheld pending evidence of progression, as determined by periodic neurologic examination and MRI. The authors estimated that $4 \%$ of their NF1 clinic population had a brainstem tumor. 